resulting in an aneurysm-like ventricular chamber no longer contributes to antegrade flow. ${ }^{6}$ The enlarged infundibulum in combination with distal stenosis may lead to RVOT turbulence and loss of kinetic energy further negatively contributing to RV remodeling. In contrast, an inverse trapezoid shape may reflect preservation of a relatively small (but contractile) infundibulum and supra-annular patching of the PA. Proximal stenosis leaving segments that are not actively contributing to forward flow distal also reduces regurgitation in part due to a more restrictive ventricular physiology.

Unfortunately, Shen and colleagues ${ }^{3}$ lack an analysis of the results with regard to the surgical strategy. More details on the surgical approach are needed to better understand the relationship between the chosen strategy and the subsequent morphology of the RVOT and to guide intraoperative decision making. It is also unfortunate that instead of using 3-dimensional data, only lateral-view measurements were analyzed for their main results. Although they report correlation between frontal and lateral measurements, they also stress that diameters of the RVOT and mid main PA were larger in lateral projections, but diameters of the pulmonary valve annulus and distal main PA were smaller compared with frontal projections. The hemodynamic relevance of the RVOT geometry and how it should influence surgical strategy can only be fully understood if the RVOT is captured in its entirety.

Long-term outcome of ToF is determined by the RVOT as many previous studies have already proven. Shen and colleagues ${ }^{3}$ stress once again that it is time to pay tribute to that misunderstood chamber called the right ventricular infundibulum.

\section{References}

1. Senac M. Traité de La Structure Du Coeur, de Son Action et de Ses Maladies. Paris, France: Briasson; 1749.

2. Van Praagh R, Van Praagh S. Aristotle's "triventricular" heart and the relevant early history of the cardiovascular system. Chest. 1983;84:462-8.

3. Shen W-C, Chen C-A, Chang C-I, Chen Y-S, Huang S-C, Wu M-H, et al. Outflow tract geometries are associated with adverse outcome indicators in repaired tetralogy of Fallot. J Thorac Cardiovasc Surg. 2021;162:196-205.

4. Vida VL, Guariento A, Zucchetta F, Padalino M, Castaldi B, Milanesi O, et al. Preservation of the pulmonary valve during early repair of tetralogy of Fallot: surgical techniques. Semin Thorac Cardiovasc Surg Pediatr Card Surg Annu. 2016; 19:75-81.

5. Hickey E, Pham-Hung E, Halvorsen F, Gritti M, Duong A, Wilder T, et al. Annulus-sparing tetralogy of Fallot repair: low risk and benefits to right ventricular geometry. Ann Thorac Surg. 2018;106:822-9.

6. McKenzie ED, Maskatia SA, Mery C. Surgical management of tetralogy of Fallot: in defense of the infundibulum. Semin Thorac Cardiovasc Surg. 2013;25: 206-12.

\title{
Commentary: More is not always better
}

\section{Tracy R. Geoffrion, MD, MPH}

Advanced cardiac imaging provides ever-increasing amounts of anatomic and physiologic data on congenital heart disease. As with many things in life, more is not always better. To surgeons, more data are better when they inform our decision making and thus improve surgical outcomes.

\footnotetext{
From the Division of Cardiothoracic Surgery, Department of Surgery, Children's Hospital of Philadelphia, Philadelphia, $\mathrm{Pa}$.

Disclosures: The author reported no conflicts of interest.

The Journal policy requires editors and reviewers to disclose conflicts of interest and to decline handling or reviewing manuscripts for which they may have a conflict of interest. The editors and reviewers of this article have no conflicts of interest.

Received for publication Sept 30, 2020; revisions received Sept 30, 2020; accepted for publication Sept 30, 2020; available ahead of print Oct 9, 2020.

Address for reprints: Tracy R. Geoffrion, MD, MPH, Division of Cardiothoracic Surgery, Department of Surgery, Children's Hospital of Philadelphia, 3401 Civic Center Blvd, Suite 8574, Philadelphia, PA 19104 (E-mail: tracygeoffrion@gmail.com).

J Thorac Cardiovasc Surg 2021;162:210-1

$0022-5223 / \$ 36.00$

Copyright (c) 2020 by The American Association for Thoracic Surgery

http://dx.doi.org/10.1016/j.jtcvs.2020.09.127
}

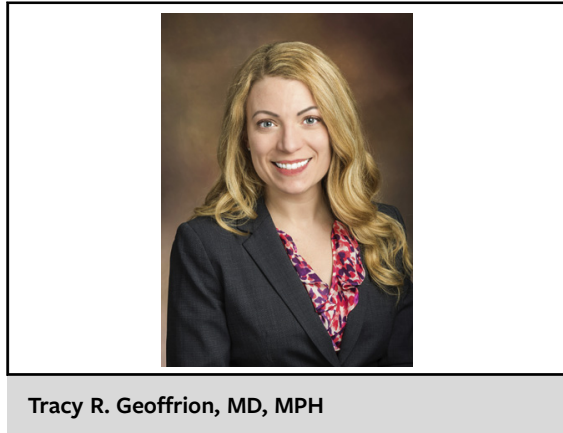

CENTRAL MESSAGE

Advanced cardiac imaging pro-

vides ever-increasing amounts of

data on congenital heart disease.

Practical application of these

data by surgeons is not always

straightforward. 
Shen and colleagues ${ }^{1}$ use cardiac magnetic resonance imaging in patients with repaired tetralogy of Fallot (TOF) to associate 4 unique right ventricular outflow tract (RVOT) morphologies with varying levels of ventricular remodeling. Although prior studies have described the characteristics of RVOT morphologies following reconstruction, this study adds the correlations of distinct geometric categories with right ventricular volume and QRS duration. Additionally, they show that size discrepancy between the branch pulmonary arteries is associated with worse long-term exercise capacity. ${ }^{1}$

Although well addressed by the authors, this study has limitations. There is no consistency in the time from cardiac magnetic resonance imaging to exercise capacity evaluation. The authors assert that because the time intervals were similar in patients with branch pulmonary artery (PA) discrepancy to those without, the influence of PA size discrepancy on exercise capacity is valid. This does not seem to adequately address the difference in the exercise capacity over time. Other factors not specific to RVOT and PA geometry that could influence performance on exercise testing include residual lesions, left ventricular dysfunction, atrioventricular valve regurgitation, noncardiac lung pathologies, ${ }^{2,3}$ and neurocognitive function. ${ }^{4}$ It is also notable that patients unable to achieve a maximal exercise effort were excluded from the analysis, which seems to impose a type of selection bias. The correlation of exercise capacity as a marker of functional status with RVOT morphology and branch PA anatomy would be more useful if the authors had controlled for confounding factors and included all exercise data, even the poor performers.

When considering applicability of this study, it is important to note that the authors describe a homogeneous population that does not represent the entire spectrum of patients with repaired TOF. All patients in this cohort underwent transventricular repair with a patch and had significant residual pulmonary insufficiency. However, there are a variety of techniques that can be employed to repair TOF and many surgeons utilize a right atrial approach to avoid potential deleterious effects of a ventriculotomy., ${ }^{5,6}$ Additionally, the mean age at complete repair in this study is 2.5 years and does not include any infant or neonatal repairs, which are not uncommon in the current era. ${ }^{7,8}$

In their conclusion, the authors endorse a proactive approach to branch PA stenosis and less-extensive incision/patching of the RVOT as beneficial for preservation of mechanics, without making a practical association to the geometric categories they defined. This does not seem novel or additive to the surgical literature. The article is well composed, and the findings could prove helpful for device development and percutaneous intervention in the RVOT. That said, it remains to be seen how we can use the data in this study to improve surgical outcomes.

\section{References}

1. Shen W-C, Chen C-A, Chang C-I, Chen Y-S, Huang S-C, Wu M-H, et al. Outflow tract geometries are associated with adverse outcome indicators in repaired tetralogy of Fallot. J Thorac Cardiovasc Surg. 2021;162:196-205.

2. Ginde S, Earing MG. When the heart is not to blame: managing lung disease in adult congenital heart disease. Prog Cardiovasc Dis. 2018;61:314-9.

3. Rowe SA, Zahka KG, Manolio TA, Horneffer PJ, Kidd L. Lung function and pulmonary regurgitation limit exercise capacity in postoperative tetralogy of Fallot. $J$ Am Coll Cardiol. 1991;17:461-6.

4. Cohen S, Earing MG. Neurocognitive impairment and its long-term impact on adults with congenital heart disease. Prog Cardiovasc Dis. 2018;61:287-93.

5. Dietl CA, Cazzaniga ME, Dubner SJ, Pérez-Baliño NA, Torres AR, Favaloro RG Life-threatening arrhythmias and RV dysfunction after surgical repair of tetralogy of Fallot. Comparison between transventricular and transatrial approaches. Circulation. 1994;90(5 Pt 2):II7-12

6. Talwar S, Anand A, Siddarth B, Ramakrishnan S, Choudhary SK Airan B. Early right ventricular function following trans-right atria versus trans-right atrial, trans-right ventricular repair of tetralogy of Fallot: results of a prospective randomized study. Ann Pediatr Cardiol. 2019; $12: 3-9$

7. Loomba RS, Buelow MW, Woods RK. Complete repair of tetralogy of Fallot in the neonatal versus non-neonatal period: a meta-analysis. Pediatr Cardiol. 2017;38: 893-901.

8. Bailey J, Elci OU, Mascio CE, Mercer-Rosa L, Goldmuntz E. Staged versus complete repair in the symptomatic neonate with tetralogy of Fallot. Ann Thorac Surg. 2020;109:802-8. 